\title{
Gorontalo
}

Journal of Government and Political Studies

Volume 4 - NO. 1 - April 2021

P-ISSN: 2614-2120 E-ISSN: 2614-2104

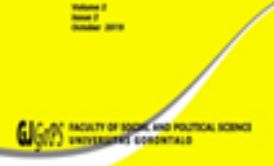

\section{Manajemen Strategi Badan Penanggulangan Bencana Daerah dalam Pencegahan Kebakaran Hutan di Kabupaten Ketapang}

\author{
Tiwi Chandya \\ Universitas Singaperbangsa Karawang \\ Jalan HS. Ronggo Waluyo, Pusuerjaya, Kec. \\ Telukjambe Timur Kab. Karawang \\ chandyatiwi@gmail.com
}

Received: 10th January 2021; Revised: 14th March 2021; Accepted: 18th March 2021;

\begin{abstract}
This research departs from an event that often occurs every year in Indonesia, namely forest fires. The high rate of forest fires that occur almost every year in Ketapang Regency raises the question of why Ketapang Regency is a region prone to this incident. This research uses descriptive qualitative method. The technique of collecting data was carried out by observation, interviews and documentation. Data were taken from selected sources based on purposive sampling technique. This study uses Fred R. David's Strategic Management theory, namely: Strategy Formulation, Strategy Implementation and Strategy Evaluation. The results of this study indicate that there are many factors that make Ketapang District experience high levels of forest fires every year. BPBD has made maximum efforts in preventing forest fires by managing its time and performance strategy for Ketapang Regency, however there are several other factors that have resulted in the relatively high number of forest fires, namely the existence of peat forest areas that are prone to burning and land clearing activities by burning Ketapang Regenc, especially BPBD has made efforts to prevent the number of forest fires in Ketapang District.
\end{abstract}

Keywords: forest fires; strategic management

\begin{abstract}
ABSTRAK
Penelitian ini berangkat dari suatu peristiwa yang kerap terjadi setiap tahunnya di Indonesiayaitu Kebakaran hutan. Tingginya angka kebakaran hutan yang terjadi hampir disetiap tahunnya di Kabupaten Ketapang menimbulkan pertanyaan bagaimana manajemen strategi khususnya BPBD sebagai stakeholder dari Pemerintah Kabupaten Ketapang yang menjadi wilayah yang rawan terhadap kejadian ini. Penelitian ini menggunakan cara kualitatif deskritif. Teknik Pengumpulan data dilakukan dengan observasi, wawancara dan dokumentasi. Data diambil dari narasumber yang ditentukan berdasarkan Teknik purposive sampling. Penelitian ini menggunakan teori Manajemen Strategi Fred R. David, yaitu : Formulasi Strategi, Implementasi Strategi dan Evaluasi Strategi. Hasil penelitian ini menunjukan bahwa banyak faktor yang menjadikan Kabupaten Ketapang sering mengalami kebakaran hutan yang cukup tinggi setiap tahunnya. BPBD telah berupaya maksimal dalam pencegahan kebakaran hutan dengan melakukan manajemen strategi waktu dan kinerjanyauntuk Kabupaten Ketapang, namun ada beberapa faktor lainnya yang mengakibatkan angka kebakaran hutan masih relatif tinggi yaitu adanya wilayah hutan gambut yang rawan terbakar serta adanya kegiatan pembukaan lahan dengan cara membakar Kabupaten Ketapang, khususnya BPBD telah
\end{abstract}


berupaya melakukan pencegahan untuk dapat menekan angka kebakaran hutan di Kabupaten Ketapang.

\section{Kata Kunci : kebakaran hutan; manajemen strategi}

\section{PENDAHULUAN}

Bencana adalah peristiwa atau rangkaian peristiwa yang mengancam dan mengganggu kehidupan dan penghidupan masyarakat yang disebabkan, baik oleh faktor alam atau faktor non alam maupun factor manusia sehingga mengakibatkan timbulnyakorban jiwa manusia, kerusakanlingkungan, kerugian harta benda, dan dampak psikologis. Bencana yang sering terjadi di Indonesia hampir setiap tahun salah satunya adalah kebakaran hutan. Dampak negatif yang ditimbulkan karena kebakaran hutan sangatlah beragam, mulai dari kerusakan ekologi, menurunnya keanekaragaman hayati, dan dampak paling menonjol yaitu kabut asap yang dapat mengganggu kesehatan manusia dan aktivitas- aktivitas transportasi di darat, udara dan laut bahkan masalah kebakaran hutan di Indonesia masuk dalam bencana secara global karena dampak dari kebakaran hutan telah dirasakan oleh negara- negara tetangga seperti Singapura, Malaysia, Thailand dan Filipina. Maka dari itu, diperlukan perhatian besar dalam pencegahan bencanakebakaran hutan di Indonesia.

Provinsi Kalimantan Baratmerupakan salah satu Provinsiyang mengalami Kebakaran hutan sangat parah dengan luas kebakaran pada tahun 2018 mencapai 68.422,03 Hektar kemudian mengalami kenaikan bahkan hampir dua kali lipat daritahun sebelumnya sebanyak 151.919,00 Hektar. Badan Meteorologi Klimatologi dan Geofisika Supadio Pontianak menyebutkan sepanjang bulan Agustus 2019 terdapat sejumlah 7.655 titik api yang tersebar di 12 Kabupaten. Terbanyak terdapatdi Kabupaten Ketapang dengan jumlah 2.126 titik api (Data Sipongi 2020).

Wilayah hutan diKabupaten Ketapang sangat rawan mengalami kebakaran apalagi saat memasuki bulan kemarau. Salah satu penyebabrawan kebakaran di Kabupaten Ketapang yaitu karena kepemilikan hutan gambut 284.506 Hektar (KLHK Kab.Ketapang 2020), diketahui bahwa pada saat lahan gambut berada dalam keadaan kering, tanaman dan semak belukar pada lahan gambut akan lebih mudah terbakar. Kebakaran pada hutan gambut memiliki tingkat kesulitan yang tinggi dalam pemadamannya hal ini karena api menyebar tidak menentu secara perlahan di bawah permukaan melalui pori-pori gambut dan akar semak belukar. Selain itu, adanya kegiatanmembuka lahan oleh para petani untuk memperluas maupun membuka lahan untuk ditanami sebagai lahan perkebunan makinmemparah keadaan tersebut.

Kebakaran hutan merupakan ancaman yang serius terhadap kelangsungan hidup masyarakat dan kelestarian lingkungan hidup yang menyebabkan kerugian secaraglobal dibidang ekonomi, ekologi, sosial, budaya, pendidikan dan kesehatan. Maka dari itudiperlukannya langkah pencegahan yang serius untuk menyikapi masalah tersebut. Hal ini bahkan diamanatkan dengan dikeluarkan Instruksi Presiden Nomor 11 Tahun 2015 tentang peningkatan pengendalian kebakaran hutan dan lahan untuk dilakukan pencegahan bencana kebakaran hutan.

Selain dorongan pusat pemerintah daerah khususnya BPBD juga telah berupaya semaksimal mungkin namun masih belum dapat terlaksana dengan optimal hal ini dapat dilihat dari jumlah titik panas dan kebakaran hutan sebagai berikut yaitu pada tahun 2016 dengan titik panas 257 dan kebakaran 
hutan 232,81 hektar lalu mengalami penurunan tahun 2017 dengan tiitk panas 143 dan kebakaran hutan 13 hektar kemudian mengalami peningkatan yang sangatsignifikan pada tahun 2018 dengan titik panas 1,027 dan kebakaran hutan 132,94 hektar. Dengan data tersebut dapat diketahui bahwa kebakaran hutan masih kerap terjadi dantelah menjadikan kebakaran hutan di Kabupaten Ketapang menjadi salah satu bencana yang mesti mendapatkan perhatian yang serius lagi khususnya BPBDKabupaten Ketapang.

\section{Tabel 1 Titik Panas dan Luas Kebakaran Hutan dan Lahan (ha) diKabupaten Ketapang 2016-2018}

\begin{tabular}{lrll}
\hline \multirow{2}{*}{ Parameter } & \multicolumn{3}{c}{ Tahun } \\
\cline { 2 - 4 } & $\mathbf{2 0 1 6}$ & $\mathbf{2 0 1 7}$ & $\mathbf{2 0 1 8}$ \\
\hline Titik Panas & 257,00 & $\begin{array}{l}143,0 \\
0\end{array}$ & 1.027 \\
\hline $\begin{array}{l}\text { Kebakaran } \\
\text { hutan dan } \\
\text { lahan (ha) }\end{array}$ & 232,81 & 13,0 & 132,9 \\
\hline
\end{tabular}

Sumber: Renstra BPBD KabKetapang

Berdasarkan data diatas maka dapat diketahui bahwasanya angka kebakaran hutan di Kabupaten Ketapang ini relative besar dengan peningkatan yang signifikan pada setiap tahunnya.Hal ini bukan merupakan sebuah prestasi melainkan panggilan darurat untuk segera diketahui bagaimana strategi yang dilakukanBPBD sebagai salah satu intansiterkait dalam pencegahankebakaran hutan di KabupatenKetapang.

Fred R. David (2017:3) mengatakan bahwa manajemen strategis adalah suatu seni dan ilmu untuk memformulasikan, menerapkan, dan mengevaluasi keputusan-keputusan lintas fungsi, dengan itu maka organisasi bisa mencapai tujuan organisasi. Sementara itu Kelly (dalam Kusumasari, 2014) mendefinisikan manajemen bencana meliputi rencanastruktur, serta pengaturan yang dibuat dengan melibatkan usaha dari pemerintah, sukarelawan dan pihak-pihak swasta dengan cara terkoordinasi dan komprehensif untuk merespons seluruh kebutuhan darurat. Oleh karena itu, manjemen bencana terdiri dari semua perencanaan, pengorganisasian, dan mobilisasi sumber daya yang dibutuhkan untuk menangani semua fase bencana sebagai peristiwa alam yang unik.

Dari pengertian diatas, dapat diketahui bahwa manajemen strategi memiliki arti suatu seni atau ilmu untuk memformulasikan, menerapkan, dan mengevaluasi dengan perencanaan yang strategis dengan memperhatikan beberapa sumber daya yang dimiliki sehingga dapat mencapai tujuan tertentu serta untuk merespons seluruh kebutuhan darurat dalam memobilisasi sumber daya yang dibutuhkan untuk menangani semua fase bencana sebagai peristiwa alam yang unik.

Pada penelitian ini, peneliti menelusuri beberapa skripsi dan jurnal hasil penelitian terdahulu yang pokok bahasannya serupa mengenai Manajemen Strategi BPBD dalam mengatasi permasalahan kebakaran hutan. Pertama, hasil penelitian inimengkaji tentang perencanakan pencegahan kebakaran hutan dan lahan yang ada di Kabupaten Kuantan Singingi. Penelitian tersebut ditulis oleh 
Destari, N. S dengan menggunakan pendekatan kualitatif. Destari, N. S menggunakan Teori Manajemen Pemerintah Menurut Zaidan Nawawi dalam menganalisis permasalahan kebakaran hutan yang terjadi. Selain itu, penelitian Destari. N. S juga lebih memfokuskan pembahasan pada bagaimana manajemen pemerintah yang ada padaKabupaten Kuantan Singingi.

Dalam penelitian Destaru. N.S ini memiliki hasil penelitian bahwa dalam merencanakan pencegahan kebakaran hutan dan lahan yang ada di Kabupaten Kuantan Singingi pemerintah harus lebih memperhatikan anggaran dana untuk mencegah terjadinya kebakaran hutan. Kegagalan dalam mencegah kebakaran di Kabupaten Singingi adalah sumber daya manusia yang tidak profesional, prasarana dan sarana kurang memadai atau tidak lengkap, rendahnya penegakan hukum dan kekurangan dana anggaran. Di Kabupaten Singingi harus diadakan pembagian wilayah agar memudahkan untuk mengetahui titik api. Sedangkan hasil penelitian pada penelitian ini yaitu manajemen strategi badan penanggulangan bencana daerah dalam pencegahan kebakaran hutan di Kabupaten Ketapang, dimana kegagalan pada perencanaan ini didasari oleh beberapa factor yaitu kegiatan masyarakat dan keadaan alam.

Penelitian selanjutnya dilakukan oleh Geovani Meiwanda dengan judul Kapabilitas Pemerintah Daerah Provinsi Riau: Hambatan dan Tantangan Pengendalian Kebakaran Hutan dan Lahan. Penelitian ini menitik beratkan analisis pada kapabilitas yang dijalankan Pemprov Riau selama ini dalam pengendalian kebakaran hutan yang terkesan lengah karena berulang terus menerus, serta apakah faktor kendala dan kekurangan berpengaruh dalam mengatasi kebakaran hutan tersebut (Meiwanda, 2016). Penelitian senada dilakukan oleh Hani Syarifah dkk. dengan judul Kapabilitas Badan Penanggulangan Bencana Daerah Kota Balikpapan dalam Penanggulangan Bencana Kebakaran Hutan dan Lahan Penelitian ini bertujuan untuk menganalisis kapabilitas BPBD Kota Balikpapan dalam mengendalikan kebakaran hutan dan lahan. Sejauh mana tantangan dan hambatan memberi pengaruh dalam kapabilitas dari pemerintah Kota Balikpapan. Peran BPBD Kota Balikpapan akan menjadi tolok ukur pemahaman yang dimiliki pemerintah daerah dalam pengendalian yang telah dilaksanakan selama ini sesuai dengan keadaan dan tantangan yang selalu berkembang (Syarifah, 2020).

Dengan melihat penelitian-penelitian sebelumnya maka dapat kita temukan bahwa kebakaran hutan memang menjadi fenomena yang terjadi dan merugikan masyarakat baik secara ekonomi maupun sosial. Oleh karena ini diperlukan keterlibatan penuh dari pemerintah dalam mencegah dan menanggulangi hal tersebut. Berdasar hal tersebut peneliti kemudian mengangkat studi yang sama dengan melihat fenomena yang terjadi di Kabupaten Ketapang. Telah dijelaskan sebelumnya bahwa kebakaran hutan menjadi masalah di wilayah ini, untuk itu penting untuk menganalisis keterlibatan pemerintah khususnya BPBD dalam menanggulangi kebakaran hutan dan meminimalisir dampak yang ditimbulkannya.

\section{METODE PENELITIAN}

Metode penelitian yang digunakan peneliti dalam penelitian ini adalah menggunakan pendekatan kualitatif dengan menggunakan sumber daya primer dan sekunder. Teknik pengumpulan data dilakukan dengan 3 strategi yaitu dengan observasi, wawancara, dokumentasi serta trigulasi data yang mana 
terdiri dari reduksi data, penyajian data serta kesimpulan. Data-data diperoleh dengan menelusuri sumber bacaan terkait dengan kebakaran hutan dan peran pemerintah di dalamnya. Selanjutnya wawancara dilakukan dengan mendatangi langsung informan dari pemerintah daerah Kabupaten Ketapang.

\section{HASIL DAN PEMBAHASAN}

Berdasarkan hasil penelitian yang merupakan penjelasan mengenai data selama penelitian di lapangan terhadap Manajemen Strategi Badan Penanggulangan Bencana Dearah dalam Pencegahan Kebakaran Hutan di Kabupaten Ketapang, diperoleh data dan informasi melalui observasi dan wawancara mendalam terhadap informan yang ditemui dilapangan serta dokumentasi. Hasil penelitian di lapangan mengacu pada tiga indikator manajemen strategi menurut Fred R. David (2017:3) yaitu formulasi strategi, implementasi strategi dan evaluasi strategi.

\section{Formulasi Strategi}

Perumusan atau formulasi strategi mencakup pengembangan visi dan misi, identifikasi peluang dan ancaman eksternal organisasi, menentukan kekuatan dan kelemahan internal, menetapkan tujuan jangka panjang, merumuskan alternatif strategi, dan memilih strategi tertentu yang akan dilaksanakan untuk mencapai tujuan Isu-isu dalam perumusan strategi mencakup penentuan program dan bidang apayang akan dimasuki/ dilaksanakan.

Pertama, Formulasi strategi menggambarkan dimana sebuah organisasi ini bisa menerangkan suatu perencanaan. Dalam hal ini BPBD bertujuan menjadikan Kabupaten Ketapang menjadi tangguh dalam penyelenggaraan kebencanaan. Dalam hal ini upaya yang dilakukan adalah dengan melaksanakan penyelenggaraan penanggulangan bencana secara terencana, terpadu, menyeluruh dan berkelanjutan secara adil dan merata. Pencegahan terhadappermasalahan kebakaran hutan yang ada di Kabupaten Ketapang yang memiliki daerah rawan serta risiko tinggi terhadap kebakaran hutan bencana banjir yang tergolong tinggi adalah wujud menjadikan Ketapang menjadi daerah yang tangguh.

Pada bagian peninjauan internal yang ada pada Kabupaten Ketapang ditemukan bahwa faktor dari persoalan yaitu adanya kebiasaan masyarakat dalam membuka lahan dengan cara membakar hutan dimana pembakaran hutan ini bertujuan untuk membuat tanah menjadi subur, sedangkan peninjauan eksternal karena kondisi alam seperti musim serta lahan gambut yang cukup luas yang ada diKabupaten Ketapang.

Dalam mengurangi risiko potensi kebakaran hutan di Kabupaten Ketapang dengan merumuskan formulasi strategi untuk pencegahan kebakaran hutan di Kabupaten Ketaoang dengan organisasi Pemerintah Daerah (OPD) terkait. Rumusan strategi yang dilakukan oleh BPBD Kabupaten Ketapang dalam pencegahan kebakaran hutan di Kabupaten Ketapang dengan melakukan tindakan pra bencana yang di dalamnya ada pencegahan dan kesiapsiagaan. Kemudian pada saat bencana terjadi, yang mana dilakukannya upaya kedaruratandan pendistribusian logistik. Kemudian selanjutnya adalah langkah setelah bencana yang fokus pada usaha merehabilitasi dan rekonstruksi dari dampak bencana. Hal ini diharapkan mendapatkan hasil yang baik yaitu meminimalisir risiko/dampak bencana atau bahkan dapat mencegah kejadian 
bencana.

\section{Implementasi Strategi}

Kedua adalah Implementasi Strategi, berdasarkan perumusanstrategi yang sudah dibuat oleh BPBD Kabupaten Ketapang dalam penyelenggaraan penanganan kebakaran hutan di Kabupaten Ketapang ditetapkan mulai dari pra bencana, saat bencana, dan pasca bencana. Pada fase pra bencanayangmana BPBD sendiri lebih memfokuskan pada fase ini yangmana terdiri dari pencegahan dan kesiapsiagaan. Pada tahan prabencana ini BPBD sendiri telah melakukan pembangunan sekat kanal untuk pencegahan terhadap lahan gambut, sekat kanal iniberfungsi untuk menyimpan air sehingga lahan gambut tersebut tidak mudah terbakar pada musim kemarau. Selain itu juga, BPBD sendiri melakukan komunikasi dan sosialisasi terhadap masyarakat di daerahdaerah rawan untuk mengedukasi masyarakat. Untuk kesiapsiagaan sendiri, $\mathrm{BPBD}$ rutin melakukan monitoring dan pemantauan dengan alat drone pemantauan dengan alat ini bermaksud untuk dapat melihat titik rawan panas yang sulit dijangkau.

Pada fase saat terjadi kebakaran hutan sendiri, BPBD sudah mempunyai tim reaksi cepat. Tim reaksi cepat adalah tim yang dibentuk untuk merespon dengan segera jika bencana terjadi dengan segera mendatangi tempat kejadian untuk mengevakuasi korban bencana dengan segera tempat kejadian untuk mengevakuasi korban bencana dengan segera yang dilakukan BPBD dengan memberikan fungsi komando kepada instansi lintas sectoral seperti TNI dan POLRI pada saat tanggap darurat.

Selain sudah memiliki tim reaksi cepat, BPBD juga membentuk kelompok masyarakat peduli api. Masyarakat Peduli Api adalah masyarakat yang secara sukarela peduli terhadap pengendalian kebakaran hutan dan lahan yang telah dilatih/diberi pembekalan serta dapat diberdayakan untuk membantu kegiatan pengendaliankebakaran hutan. Pembentukankelompok masyarakat peduli api ini diharapkan dapat mengajak masyarakat turut serta dan sadar akan bahaya dari kebakaran hutanitu sendiri.

\section{Evaluasi Strategi}

Ketiga adalah evaluasi strategi yang telah dirumuskan dan diimplementasikan oleh BPBD Kabupaten Ketapang dalam pencegahan kebakaran hutan di Kabupaten Ketapang. Dalam evaluasi BPBD melakukan penilaian kinerja pada saat kebakaran terjadi untuk melihat sudah sejauh mana dampak strategi yang diterapkan untuk menanggulangi kebakaran hutan di Kabupaten Ketapang. Kemudian pengukuran strategi dalam implementasi agar diketahui mana saja yang tidak berjalan dan berhasil dalam pencegahan kebakaran hutan di Kabupaten Ketapang. Tahapan-tahapankebencanaan seperti saat sebelum bencana terjadi hingga pada setelah bencana masih terdapat kelemahan dalam implementasinya. Hal ini juga sejalan dengan adanya penilaian kepuasaan masyarakat akan strategi yang sudah dirumuskan. Pada masyarakat Kabupaten Ketapang sendiri masih banyak mendorong BPBD untuk melakukan evaluasi. Maka dari itu, dalam melakukan evaluasi BPBD rutin melaksanakan agenda evaluasi strategi penanganan bencana pada rapat yang dilakukan oleh BPBD untuk menilai strategi. Evaluasi Strategi dalam manajamen strategi Badan Penanggulangan Bencana Daerah Kabupaten 
Ketapang dalam pencegahan kebakaran hutan di Kabupaten Ketapang belum optimal. Hal ini terlihat dari masih ditemukan kekurangan pada internal BPBD sendiri seperti kurangnya personil pada BPBD maupun faktor eksternal yang ada seperti rusaknya sekat kanal serta pernyataan beberapa kalangan masyarakat yang merasa kurang optimalnya kinerja dari BPBD.

\section{PENUTUP}

Strategi formulasi dalam manajemen strategi Badan Penanggulangan Bencana Daerah dalam pencegahan kebakaran hutan di Kabupaten Ketapang dalam formulasi ini telah dirumuskan BPBD dengan Organisasi Perangkat Daerah lainnya yang dibantu serta masyarakat sebagai pendukung saran dan solusi sehingga perumusannya sudah dapat dikatakan optimal. Hal ini dibuktikan dengan dirumuskannya proses strategi penanganan bencana yangmana dimulai dari pra bencana, saat terjadi bencana, dan pasca bencana yang dibuat oleh BPBD sebagai upaya pencegahan kebakaran hutan di Kabupaten Ketapang. Dengan adanya langkah strategi yang dirumuskan arah langkah penyelenggaraan penanganan kebakaran di Kabupaten Ketapang jadi tergambarkan. Sehingga secara umum sebagai tahapan perumusan strategi pencegahan kebakaran hutan di Kabupaten Ketapang sudah cukup berjalan baik.

Implementasi Strategi dalam manajemen strategi Badan Penanggulangan Bencana Daerah dalam pencegahan kebakaran hutan di Kabupaten Ketapang dalam implementasinya belum optimal. Bahwa dalam pelaksanaaan strategi kebakaran hutan tersebut pada dari proses prabencana, saat bencana terjadi, dan setelah bencana masing masing dalam pelaksanaannya masih belum dapat mengurangi persoalan kebakaran di Kabupaten Ketapang. Berbagai kelemahan terlihat dalam tahapan-tahapan khususnya pada tahapan pencegahan yang sudah dibuat oleh BPBD untuk menangani permasalahan kebakaran di Kabupaten Ketapang. Hal tersebut terlihat darisekat kanal yang rusak sehingga mengurangi fungsi dari alat tersebut menjadi optimal, kemudian pengadaan sosialisasi yang belum rutin dan berkelanjutan hal ini mengakibatkan penyampaian informasi yang tidak sepenuhnya. Evaluasi Strategi dalam manajamen strategi Badan Penanggulangan Bencana Daerah Kabupaten Ketapang dalam pencegahan kebakaran hutan di Kabupaten Ketapang. Evaluasi sudah terlaksanakan tetapi belum optimal. Hal ini terlihat dari pernyataan beberapa kalangan masyarakat yang merasa kurang optimalnya kinerja dari BPBD.

\section{DAFTAR PUSTAKA}

Anita, Sri. 2008. Strategi Pembelajaran. Surakarta: Alfabet.

Arikunto, S. 2013. Prosedur Penelitian: Suatu Pendekatan Praktik. Jakarta: Rineka Cipta. Choliq, Abdul. 2011. Pengantar Manajemen. Semarang: Rafi Sarana Perkasa.

Creswell, John W. 2013. Research Design, Pendekatan Metode Kualitatif, Kuantitatif danCampuran. Yogyakarta: PustakaPelajar.

Danial Nanan Wasriah. 2009. Metode Penulisan Karya Ilmiah. Bandung: Laboratorium Pendidikan Kewarganegaraan.

David, Fred R. 2017. Manajemen Strategik Suatu Pendekatan Keunggulan Bersaing. Jakarta:Salemba Empat. 
Faisal, S. 2001. Format-Format Penelitian Sosial. Jakarta: Raja Grafindo.

Hasibuan, Malayu S.P. 2011. Manajemen Sumber Daya Manusia. Bandung: Bumi Aksara.Hasibuan, Melayu. 2012. Manajemen Sumber Daya Manusia. Bandung: PT BumiAksara. Handoko, T. Hani. 2011. Manajemen Personalia SumberDaya Manusia. Yogyakarta:BPFE.

Hatta. 2008. Pedoman Manajemen Informasi Kesehatan di Sarana Pelayanan. Kesehatan.Jakarta: UI Press.

Meiwanda, Geovani. "Kapabilitas Pemerintah Daerah Provinsi Riau: hambatan dan tantangan pengendalian kebakaran hutan dan lahan." Jurnal ilmu sosial dan ilmu politik 19.3 (2016): 251-263.

Notohadinegoro. 2006. Pembakaran dan Kebakaran Lahan. Yogyakarta: UGM

Nugroho. 2000. Keperawatan Gerontik.Jakarta: Salemba.

Sedarmayanti, H. J.2014. Manajemen Sumber Daya Manusia. Bandung: Refika Aditama.

Sugiyono. 2017. Metode Penelitian Pendekatan Kuantitatif, Kualitatif, Kombinasi dan R\&D. Bandung: Alfabeta

Syaufina. 2008. Kebakaran hutan dan Lahan di Indonesia: Perilaku Api, Penyebab dan Dampak Kebakaran. Malang: PT.Bayu Media.

Syarifah, H., Poli, D. T., Ali, M., Rahmat, H. K., \& Widana, I. D. K. K. (2020). Kapabilitas Badan Penanggulangan Bencana Daerah Kota Balikpapan dalam Penanggulangan Bencana Kebakaran Hutan dan Lahan. NUSANTARA: Jurnal Ilmu Pengetahuan Sosial, 7(2), 398-407.

Qodriyatun, S. N. 2014. Kebijakan Penanganan Kebakaran Hutan dan Lahan. Bandung: PT Bumi Aksara

\section{Peraturan Perundang-Undangan dan Dokumen}

Data Sipongki 2020

Undang-Undang Nomor 4 Tahun 2001 tentang pengendaliankerusakan dan atau pencemaran lingkungan hidup

Peraturan Menteri kehutanan Nomor 12 Tahun 2009 tentang Pengendalian Kebakaran Hutan

Peraturan Gubernur Nomor 39 Tahun 2019 Tentang Pencegahan dan Penanggulangan Kebakaran Hutan dan Lahan.

Instruksi Presiden Nomor 11 Tahun 2015 Tentang PeningkatanPengendalian Kebakaran Hutan dan Lahan

Internet

https://www.kompasiana.com/y etti/59ab65cfcbb34c06d3769d0 2/kebakaranhutan (diakses bulan September 2020) 